\title{
Os Circuitos da Economia Urbana na Perspectiva do Turismo em Belém, Pará
}

\author{
The Urban Economy Circuits in the Tourism Perspective in Belém, Pará
}

\author{
Ágila Flaviana Alves Chaves Rodrigues ${ }^{1}$
}

\begin{abstract}
RESUMO - O presente trabalho discute o turismo e sua relação com a teoria dos circuitos da economia urbana proposta por Milton Santos no final da década de 1970, considerando as suas atualizações. Buscou-se contribuir na compreensão de dinâmicas particulares do processo de urbanização de Belém, capital do estado do Pará, dentro das especificidades impostas pela atividade turística na orla central e sul da cidade. Com o intuito de atingir tal objetivo, realizou-se uma revisão bibliográfica sobre a teoria dos circuitos da economia, bem como a análise documental de planos e projetos governamentais, tendo o auxílio da observação sistemática não-participante da paisagem. Concluiu-se que as atuais propostas de intervenções na orla central e sul visam refletir as novas dinâmicas impostas pelo Estado em sua relação com os circuitos econômicos do turismo, que alteram de modo significativo a divisão social do trabalho sem, contudo, excluir suas antigas dimensões.
\end{abstract}

Palavras-chave: Circuitos Econômicos; Políticas de Turismo; Belém; Orla Sul; Orla central.

ABSTRACT - The present paper brings a discussion about tourism in its relation with the theory of the urban economy circuits proposed by Milton Santos in the 70's, considering its updates. It tried to understand the particular dynamics of the urbanization process in Belém, Pará capital, Brazil, within the specificities imposed by the tourist activity in the central and southern border of the city. Then, a bibliographical review was carried out on the theory of the economic circuits, as well as the analysis of governmental plans and projects, with the support of a non-participant systematic observation of the landscape. It was Concluded, that the current proposals for interventions in the central and south waterfront demonstrate the new dynamics imposed by the state in relation to the tourism economic circuits, which significantly alter the social division of labor without, however, excluding other previous dimensions.

Keywords: Economic Circuits; Tourism Policies; Belém; Southern Waterfront; Central Waterfront.

\footnotetext{
${ }^{1}$ Doutoranda em Desenvolvimento Socioambiental pela Universidade Federá do Pará / Núcleo de Altos Estudos Amazônicos (UFPA / NAEA). Mestrado em Planejamento do Desenvolvimento pela UFPA / NAEA. Especialização em Gestão de Cidades e Sustentabilidade pela UFPA / Núcleo de Meio Ambiente. Bacharelado em Turismo pela UFPA. Professora substituta no Instituto Federal de Educação, Ciência e Tecnologia do Pará (IFPA - Campus Belém), no eixo de Turismo, Hospitalidade e Lazer. Pesquisadora no Grupo de Pesquisas em Ordenamento Territorial e Urbanodiversidade da Amazônia (GEOURBAM/NAEA/UFPA). E-mail: agflaviana@gmail.com
} 


\section{INTRODUÇÃO}

Belém, capital do Pará, localizada na confluência entre a Baía do Guajará e a foz do Rio Guamá, nasce e cresce a partir da orla fluvial, sendo reconhecida historicamente como ribeirinha, devido à sua estreita relação com as águas. Ao longo dos anos, os agentes do Estado vêm estabelecendo um discurso de afastamento das águas, ao ponto de considerar que Belém "cresceu de costas" para o rio.

A intencionalidade e tentativa de (re)aproximar a capital paraense da imagem de “cidade das águas" surge por meio da (re)valorização da cultura ribeirinha, iniciada pela abertura da orla para projetos que buscassem resgatar a sua face fluvial, construindo e revitalizando espaços, voltando-os para o lazer, para a arte e para o turismo (AMARAL, 2005).

A partir do ano de 1998, iniciam-se tentativas de (re)aproximação das águas, sendo o turismo capaz de gerar emprego, renda e momentos de entretenimento para a população, uma das principais justificativas de abertura da cidade para o rio. Preocupa a reprodução desse discurso, visto que alguns grupos e espaços da orla, cuja expressiva presença de elementos como barcos, feiras, portos e trapiches, apontam a existência das relações de proximidade da cidade, que ainda se mostra ribeirinha, vão sendo excluídos e afastados para longe das novas intervenções.

Também é possível observar em alguns pontos que esses mesmos elementos de cunho tradicional (ribeirinho) se misturam com práticas ligadas ao lazer e ao turismo, onde o rio, as embarcações, os pequenos portos e trapiches, adquirem novos usos. As empresas de receptivo turístico e os guias de turismo, responsáveis pela circulação de pequenos e médios grupos de visitantes, exercem uma importância considerável dentro do conjunto de atividades econômicas.

A problematização leva em conta as atuais intervenções na orla central e sul de Belém que refletem as novas dinâmicas impostas pelo turismo em sua relação com os circuitos modernos da economia urbana. Objetiva-se, por meio de revisão bibliográfica sobre a teoria dos dois circuitos da economia (SANTOS, 2004 [1979]) e suas respectivas atualizações, encontradas nos trabalhos de Silveira (2001 e 2007), Bicudo (2006) e Montenegro (2011), bem como da análise documental de planos e projetos governamentais, contando ainda com o auxílio da observação sistemática não- 
participante da paisagem das orlas central e sul da cidade, elucidar o comportamento cotidiano dos agentes que atuam com pequenas práticas de lazer e turismo. Fontes como dissertações, teses e páginas virtuais de notícias relacionadas à oferta turística em Belém foram consultadas, afim de compreender os impactos das interferências, pequenas ou grandes, que ao projetar imagens de forte apelo cultural atraem o interesse de investidores e consumidores de espaços turísticos.

Entende-se que estudos que visem analisar a forma como o turismo se apropria do espaço, (re)significando-o, pode cooperar com o planejamento, com a avaliação e a com a execução das políticas públicas, fazendo com que estas levem em consideração as especificidades locais.

\section{APORTE TEÓRICO SOBRE OS CIRCUITOS DA ECONOMIA URBANA NA PERSPECTIVA DO TURISMO EM BELÉM}

Os espaços do turismo, compostos por fixos e fluxos, sistemas de objetos e sistemas de ações, compreendem as atividades do circuito inferior e do circuito superior da economia urbana, concentrados em mercados distintos, porém, interdependentes à medida que interagem entre si (SANTOS, 2004 [1979]).

O circuito superior é o espaço das minorias economicamente privilegiadas e institucionalizadas. As atividades envolvem alta tecnologia, publicidade e propaganda, sendo o apoio governamental fundamental, por sua capacidade de viabilizar capital social fixo e infraestrutura (SANTOS, 2008). Quando voltado para o turismo, possui uma organização altamente burocrática, em sua maioria de grau empregatício assalariado e reduzido; o volume de negócios é gigantesco e acumulativo; um hotel de luxo por exemplo, mesmo quando não pertencente a uma rede hoteleira, é detentor de valores de venda fixos e de atributos sofisticados; os créditos bancários facilitam a compra avista ou mesmo a prazo dos serviços, diminuindo os riscos de prejuízos; a manutenção de custos fixos (salários, água, luz, telefone, internet) faz-se importante à garantia e permanência no mercado em longo prazo.

O circuito inferior é representado pelo conjunto de sujeitos que vivem basicamente da sua força de trabalho, sem a utilização intensiva do capital, cujas vendas em pequena escala, o comércio e a prestação de serviços menos modernos e com pouca 
tecnologia compõem a base da economia. É representado pelas atividades da população pobre, possuindo diferentes formas de organização (MONTENEGRO, 2011). Podem ser criadas possibilidades de existência e permanência do turismo nesse circuito, prevalecendo o caráter mais tradicional, como o comércio artesanal, alimentício e de lazer. No quadro 1 encontram-se sistematizadas as principais características dos dois circuitos:

\section{QUADRO 1 - CIRCUITOS DA ECONOMIA URBANA: COMPOSIÇÃO E CARACTERISTICAS}

\begin{tabular}{|c|c|c|}
\hline Atributos & Circuito Superior & Circuito Inferior \\
\hline Tecnologia & Capital intensivo & Trabalho intensivo \\
\hline Organização & Burocrática & Primitiva \\
\hline Capitais & Importantes & Reduzidos \\
\hline Emprego & Reduzido & Volumoso \\
\hline Assalariado & Dominante & Não obrigatório \\
\hline Estoques & Grande quantidade e/ou alta qualidade & $\begin{array}{c}\text { Pequena quantidade/ Qualidade } \\
\text { inferior }\end{array}$ \\
\hline Preços & Fixos (em geral) & $\begin{array}{c}\text { Submetidos à discussão entre } \\
\text { comprador e vendedor (haggling) }\end{array}$ \\
\hline Crédito & Bancário institucional & Pessoal não institucional \\
\hline Margem de lucro & $\begin{array}{l}\text { Reduzida por unidade, mas importante } \\
\text { pelo volume de negócios (exceção } \\
\text { produtos de luxo) }\end{array}$ & $\begin{array}{c}\text { Elevada por unidade, mas } \\
\text { pequena em relação ao volume de } \\
\text { negócios }\end{array}$ \\
\hline $\begin{array}{l}\text { Relações com a } \\
\text { clientela }\end{array}$ & Impessoais e/ou com papéis & Diretas, personalizadas \\
\hline Custos fixos & Importantes & Desprezíveis \\
\hline Publicidade & Necessária & Nula \\
\hline Reutilização dos bens & Nula & Frequente \\
\hline Overhead capital & Indispensável & Dispensável \\
\hline Ajuda governamental & Importante & Nula ou quase nula \\
\hline $\begin{array}{c}\text { Dependência direta do } \\
\text { exterior }\end{array}$ & Grande, atividade voltada para o exterior & Reduzida ou nula \\
\hline
\end{tabular}

FONTE: Santos (2004 [1979]).

Silveira (2007, p. 3), ao compreender a cidade como um conjunto, solidário e contraditório, de divisões do trabalho, assume que "a riqueza produzida pelo circuito superior não pode ser compreendida sem a pobreza própria do circuito inferior, que este também perpetua". Os circuitos são interdependentes, enquanto o superior é constituído pelos bancos, comércio, indústria e serviços modernos amiúde orientados à exportação, o inferior é integrado por formas de fabricação que não são intensivas em capital e pelo comércio e serviços não-modernos. 
Fazendo o elo entre os dois circuitos, encontra-se o circuito superior marginal, que consiste em formas de produção menos modernas da perspectiva da tecnologia, da organização e do capital, tendo um caráter residual e emergente, variando de cidade para cidade (SANTOS, 2004). Esse circuito carrega atividades fundamentais para a circulação daqueles que fazem de um lugar um local turístico, por sua capacidade de (re)organizar a dinâmica econômica regional, formado por empresas, turistas e moradores que adquirem pacotes de passeios onde se encontram os atrativos.

Em Belém, o circuito superior revela-se, por sua importante influência infraestrutural e logística para a produção econômica regional (VELOSO; TRINDADE JÚNIOR, 2014). Nesse mesmo contexto, manifestam-se diversas pequenas porções do espaço onde o circuito inferior se impõe, como por exemplo na região insular, na orla sul e mesmo na porção central ${ }^{2}$ da cidade.

No final do século XX, inicia-se o processo de abertura da orla da cidade (mapa 1) para projetos que buscassem resgatar sua face fluvial, demonstrando a importância que o rio expressa, portanto, múltiplos usos do tempo e do espaço, materializando-se em atividades econômicas, como também, em proporções simbólicas. Foram criados ambientes voltados para o lazer e para o turismo que, em sua feição econômica, muitas vezes pode reproduzir lógicas de apropriação externas às vontades e às práticas cotidianas.

\footnotetext{
2 Trindade Júnior (2018), chamou de velho centro as áreas formadas principalmente pelos bairros da Cidade Velha e Campina que, antes, especialmente no auge da borracha, eram espaços de circulação das elites locais, e que a partir da segunda metade do século XX, passam a ser caracteriar pela forte presença do comércio popular e pelas demais práticas cotidianas associadas ao circuito inferior, tendo-se o complexo Ver-o-Peso como melhor exemplo.
} 
MAPA 1 - BELÉM: LOCALIZAÇÃO DAS INTERVENÇÕES TURÍSTICAS NA ORLA

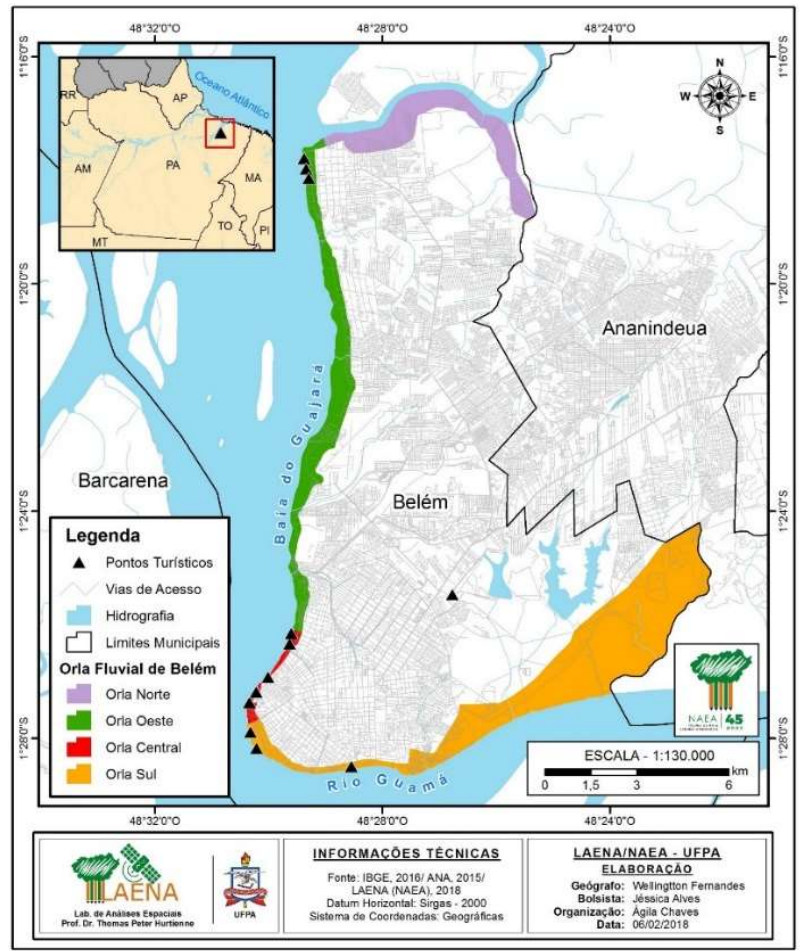

FONTE: ANA (2015); IBGE (2016); Laboratório de Análises Espaciais Prof. Dr. Thomas Peter Hurtienne (2018).

Organização: Wellington Fernandes e Ágila Chaves Rodrigues (2018).

$\mathrm{Na}$ orla central de Belém, encontram-se intervenções voltadas para o uso turístico - como o "Complexo Estação das Docas" e o "Núcleo histórico Feliz Lusitânia", de iniciativa do governo estadual; e o "Projeto Ver-o-Rio" e o "Complexo do Ver-o-Peso", implementados pela Prefeitura Municipal de Belém (AMARAL, 2005).

Em direção à parte sul, encontra-se o Programa de Reabilitação Urbana e Ambiental da Bacia da Estrada Nova (PROMABEN), também conhecido como "Portal da Amazônia”, iniciado pela gestão municipal em 2006, tendo ainda o apoio do Ministério do Turismo, cuja premissa era a de tornar a orla "livre de toda a sujeira acumulada durante anos de descaso" (MALHEIRO, 2009, p. 24).

Nas demais partes da orla sul, traduzem-se os serviços ligados à circulação fluvial, ao comércio e a algumas indústrias, além de setores ligados ao circuito inferior (TRINDADE JÚNIOR, 2005); destaca-se o Porto da Palha e a Praça Princesa Isabel, pontos de partida de embarcações de moradores que fazem travessia para as ilhas da região e para o município do Acará. 
O turismo, ao se interpor analiticamente entre os dois circuitos econômicos, aparece inserido na divisão da produção de bens materiais, que podem ser encontrados no circuito inferior e por meio da circulação de bens imateriais, como o patrimônio cultural (culinária, arte, festas, a história) e as diversas formas de uso da natureza (apoderamento de conhecimentos, inovações e práticas detidas pelas comunidades tradicionais, que vão desde as formas de cultivo e extração, até o controle biológico) visualizados no circuito superior.

Para a análise dos circuitos da economia e de suas atualizações, considera-se, em primeiro, que ambos possuem a mesma origem, não sendo sistemas fechados, pois estabelecem relações de complementaridade e de concorrência entre si (CATAIA; SILVA, 2013).

Dentre os componentes do circuito superior destaca-se a relevância da informação e das finanças, características das empresas do mercado corporativo (SILVEIRA, 2007), a exemplo da presença de empresas de entretenimento, de consultoria, de produção de informação e de operadoras turísticas, que divulgam e prestam serviços sobre os atrativos turísticos das regiões.

Fazendo o elo entre os dois circuitos, encontra-se o circuito superior marginal, que consiste em formas de produção menos modernas da perspectiva da tecnologia, da organização e do capital, tendo um caráter residual e emergente, variando de cidade para cidade (SANTOS, 2004). Esse circuito intermediário carrega atividades fundamentais para a circulação daqueles que fazem de um lugar um local turístico, por meio das empresas especializadas, os turistas adquirem pacotes, roteiros e passeios nas regiões onde estão os atrativos.

Para Silveira (2007), o circuito superior marginal é constituído de formas mistas, pertencentes tanto a atividades herdadas de divisões do trabalho pretéritas, como formas de trabalho emergentes inseridas nas atividades modernas. Nesse sentido, reforça-se o caráter interdependente dos circuitos da economia urbana, que interpretados dentro das particularidades do turismo (re)organizam a dinâmica econômica regional. 


\section{BELÉM E O PROCESSO DE URBANIZAÇÃO (TURÍSTICA)}

Desde o Ciclo da Borracha, entre os anos de 1850 a 1920, Belém torna-se destaque nacional e internacional, pelo quadro de crescimento econômico e de urbanização acelerada. Nesse momento, a paisagem urbana é incrementada por noções estéticas e higienistas, expressas nos esforços de limpeza urbana, na pavimentação das ruas e na construção de praças e jardins (NÓBREGA, 2006). Do porto eram escoados diversos produtos para a Europa e para o interior, haja vista que esse local a partir de 1850, passa a ser um destacado entreposto comercial (MALHEIROS; ROCHA, 2013).

Para Trindade Júnior e Barbosa (2016), com as medidas de renovação urbana inspiradas no modelo europeu, padronizou-se o Mercado do Ver-o-Peso e a orla central, afastou-se para longe os trapiches e seus negociadores, redirecionando o comércio de produtos regionais para áreas mais distantes e aproximando as indústrias de importante atividade fabril para a área portuária. Entretanto, os produtos locais permaneciam sendo consumidos e comercializados por boa parte da população nas feiras e pequenos portos.

Com o término desse ciclo, houve um período de expressiva estagnação econômica, e somente na década de 1960, momento marcado pela inserção de políticas territoriais de desenvolvimento regional, que visou integrar a Amazônia ao restante do País, foi impulsionado o incentivo à substituição dos rios e das ferrovias pelas rodovias, pelos incentivos fiscais, pelo início da industrialização, pela atração da mão de obra migratória e a pela vinda dos grandes projetos.

A paisagem da orla de Belém, por meio das políticas territoriais, foi modificada por empreendimentos privados, portos e atividades econômicas incentivadas por órgãos como a Superintendência do Desenvolvimento da Amazônia (SUDAM), (TRINDADE JÚNIOR, 2014), contudo, vale lembrar que embora a ocupação privada predomine em quase toda a extensão da orla, a mesma ocorreu de maneira diferenciada, conforme observado na orla sul da cidade, onde dominam alguns traços de atividades e agentes mais ligados à face "ribeirinha" e ao circuito inferior (TRINDADE JÚNIOR, 2014).

A partir da segunda metade do século XX, além da construção da Belém-Brasília, primeiro grande eixo de penetração rodoviária da Bacia Amazônica (VICENTINI, 2004), ocorreu também a abertura da base militar de Val de Cans para o tráfego de passageiros domésticos, fornecendo subsídios para a mobilidade de pessoas com a implantação de 
voos nacionais e internacionais (SUDAM, 1968). Esses dois empreendimentos como marcos centrais àquilo que se firmava a médio e longo prazo, a abertura da floresta para o capital nacional, internacional e para o turismo.

No que diz respeito ao setor de serviços hoteleiros, entre as décadas de 1970 e 1980, destacaram-se os implementos de luxo em Manaus, Santarém e Belém, como a rede de hotéis Tropical, em Manaus (1969) e a rede Horsa em Belém³ ${ }^{3}$ o que corresponde às origens dos incentivos à instalação de empresas turísticas em cidades estratégicas posicionadas na região (ANDRADE; TAVARES, 2012).

O estabelecimento de uma infraestrutura de transportes e hoteleira seria fundamental para os planos governamentais de receber grandes empresas e futuros investidores. Para Andrade e Tavares (2012), investir no turismo era a expectativa de um vantajoso custo-benefício, pois, se comparado a outras atividades econômicas, o pouco investimento e a quantidade diversificada de empregos (hotelaria, restaurantes, agências de viagens, transporte e artesanato) possibilitaria integrar a região no contexto socioeconômico e cultural do país.

Entre os anos de 1960 e 1980, o poder público promoveu o projeto de macrodrenagem do Igarapé das Almas, substituindo-o pela avenida Visconde de Souza Franco, (re)organizando-se seus usos e tipologias, onde as vilas operárias e os assentamentos informais deram lugar aos arranha-céus, centros comerciais e serviços de luxo (CARDOSO, 2015). Dentro desse período, surgem os distritos industriais de Icoaraci e Ananindeua, voltados para atividades fabris e de beneficiamento de matéria-prima. $\mathrm{O}$ estabelecimento de uma infraestrutura de transportes e hoteleira seria fundamental para receber as grandes empresas (ANDRADE; TAVARES, 2012).

O modelo econômico de turismo colocado pelos governos militares tinha como principal premissa a geração de emprego e renda. Tanto o I Plano de Turismo da Amazônia (PTA), lançado em 1977, coordenado pela Superintendência de

\footnotetext{
${ }^{3}$ Desde a década de 1950, a rede Horsa (Hotéis Reunidos S/A), considerada a primeira grande rede hoteleira do Brasil, destacava-se como a responsável pela construção de grandes empreendimentos de hospedagem no país. A partir da década de 1970, por meio de incentivos fiscais para a hotelaria desenvolvidos pela EMBRATUR, o grupo criou estabelecimentos comerciais, como o Hotel Nacional em Brasília, a convite pessoal do então presidente da república Juscelino Kubistcheck, e o originalmente denominado Hotel Nacional (Excelsior Copacabana), no Rio de Janeiro, inaugurado em 1972, com projeto arquitetônico de Oscar Niemeyer, bem como empreendimentos em São Paulo, Belém e Belo Horizonte (XAVIER, 2007). Em Belém, o grupo atuou no Hotel Excelsior Grão-Pará, atual Hotel Grão-Pará, localizado no bairro da Campina, nas proximidades da praça da República.
} 
Desenvolvimento da Amazônia (SUDAM), quanto o II PTA, voltavam-se para a contribuição na ocupação territorial ordenada e pela participação no desenvolvimento econômico e social da região, valorizando os recursos naturais e o patrimônio históricocultural (NÓBREGA, 2006).

A partir da década de 1990, dentro de um contexto neoliberal, priorizou-se a descentralização do governo federal, por meio da criação do Programa Nacional de Municipalização do Turismo (PNMT), em 1994. Posteriormente, para os primeiros anos do século XXI, o Programa de Regionalização do Turismo passou a ter o mesmo significado no que diz respeito à escala local e regional. Destaca-se ainda, a partir de 2007, as diretrizes do Plano Nacional de Turismo (PNT), estruturado pelo MTUR, onde encontra-se o Programa Nacional de Desenvolvimento do Turismo (PRODETUR), cujos objetivos buscam organizar as intervenções públicas para o desenvolvimento da atividade turística (PARÁ, 2011).

Em nível estadual, salienta-se o Plano de Desenvolvimento Turístico (PDT), que, entre os anos de 2001 a 2011, permitiu a divisão do Pará em polos turísticos: Belém, Amazônia Atlântica, Marajó, Tapajós, Xingu e Araguaia-Tocantins (PARÁ, 2001), que buscou atrair investimentos e linhas de crédito para os polos Belém, Marajó e Tapajós. Nesse processo, planejamento e gestão pública passam a tratar a cidade em formato de mercadoria e/ou de empresa, tornando-se o marketing urbano uma premissa fundamental para a consolidação das políticas.

Mais recentemente, a verticalização, aspecto importante da metropolização, consolida-se na área central de Belém, atingindo consideravelmente os bairros do Guamá, Jurunas, Terra-firme, Condor e Cremação. A especulação imobiliária revela-se com o aumento da presença de incorporadoras e construtoras nas proximidades da orla, reconhecendo a área como espaço ideal para a construção de edifícios residenciais e comerciais, com a melhor vista, arejamento e aproximação aos principais equipamentos urbanos da cidade.

Belém tem tido destaque nos veículos de comunicação locais e nacionais, por seu potencial gastronômico e biodiversidade. As novas ações, apresentadas nos planos e nos projetos governamentais e empresariais, afirmam que a culinária paraense desponta como a que melhor representa o Brasil, por suas características peculiares que remetem à origem cabocla. 
Existe a preocupação em torno da criação de uma Belém com psicosfera de "cidade da criatividade". Para isso são retirados investimentos públicos de setores sociais, transferindo-os para projetos econômicos que privilegiam poucos, aumentando, assim, o desemprego e as baixas condições de vida da população, que vai sendo cada vez mais expulsa para áreas distantes das suas antigas moradorias, acentuando de maneira considerável a pobreza.

\section{O TURISMO E O (NEM TÃO) ATUAL PROJETO DE CIDADE PARA BELÉM}

O processo de modernização de Belém pode ser observado por meio de intervenções e políticas públicas, ganhando relevância em torno de três eixos: 1) beneficiamento e exportação de minério, assim como produtos regionais (madeireiros, animais vivos da espécie bovina, combustíveis e lubrificantes, pescados, couros e peles de bovinos e equídeos, oléo de palma, frutas como cocos, castanhas, açaí e minérios como o manganês) para mercados como dos Estados Unidos, da Turquia, da China e da França (SEDEME, 2017); 2) expansão da construção civil e do mercado imobiliário (FAPESPA, 2015); 3) propagação dos setores de comércio e de serviços, com destaque para a promoção do turismo (IBGE, 2009).

Para Montenegro (2011), ao analisar as diferentes feições regionais dos circuitos da economia urbana, em especial o circuito inferior, a capital paraense assume relevante representatividade, pela densidade, pela diversidade e pela singularidade do seu circuito inferior, entrelaçado com circuitos espaciais de produção de alcance regional (SANTOS; SILVEIRA, 2001), considerando ainda a influência corporativa na urbanização da cidade.

O destaque recente nos veículos de comunicação locais e nacionais, por seu potencial cultural gastronômico e pela biodiversidade, conduzem a novas propostas de ações apresentadas nos planos e nos projetos dos agentes e promotores territoriais, ao afirmar que a culinária paraense desponta como a que melhor representa o Brasil, por suas características peculiares que remetem à origem indígena, como também pela variedade de sementes, frutos e raízes originadas da floresta. 
Dentre as propostas do governo estadual encontra-se a criação do "Centro de Gastronomia da Amazônia"4 (PARÁ, 2016). A primeira tentativa de implantação do polo gastronômico ocorreu na Casa das Onze Janelas, em 2016, contudo, não foi bem-sucedida devido à resistência de movimentos sociais ligados ao Museu de Arte Contemporânea, que funciona no mesmo local (PARÁ, 2017). A reação dos movimentos sociais e de outros agentes locais, fez com que entidades privadas interessadas em participar do processo de implementação do projeto fossem obrigadas a recuar.

Esse tipo de repercussão demonstra que a prática de venda do espaço público, mesmo sendo cada vez mais comum, não impede a ocorrência de conflitos e tensões de ordens diversas por parte daqueles que dele usufruem. Nesse primeiro momento, o uso massivo de propagandas para convencer a população das vantagens existentes nos espaços onde são comercializados produtos e serviços "gourmetizados" não foram suficientes, principalmente, por esse local se apresentar vulnerável por seu tipo de administração e histórico de conflitos.

A Secretaria de Estado de Desenvolvimento Econômico, Mineração e Energia do Pará (SEDEME, 2017), criada em 2011, responsável pela criação do Polo gastronômico (PARÁ, 2016), foi compelida a rever a sua destinação. Por meio do Procedimento de Manifestação de Interesse Social (PMIS), instrumento de comunicação pública que permite a qualquer cidadão, coletivo ou organização (institucionalizada ou não) apresentar propostas à gestão pública, realizou-se uma oitiva à sociedade, no qual o Instituto de Desenvolvimento Florestal e da Biodiversidade do Estado do Pará (IDEFLOR-Bio) manifestou-se favoravel à implantação do projeto no Parque Estadual do Utinga (PEUt) (PARÁ, 2017).

A definição do PEUt, criado em 1993, localizado na parte sul, entre os municípios de Belém e Ananindeua, como o novo espaço de localização do então Centro Global de Gastronomia e Biodiversidade, mostra como a valorização da cultura e do meio ecológico, vistos como elementos simbólicos e espaciais, vai sendo cada vez mais apropriada pelas novas políticas, cujos interesses vão além da gestão coletiva. Esse novo ambiente torna-se atraente para o capital imobiliário que avança em direção às periferias.

\footnotetext{
${ }^{4} \mathrm{O}$ decreto de criação do polo gastronômico, idealizado em 2015 e promulgado em 2016, envolveu além do governo estadual, representantes de um conjunto de organizações sociais, como o Instituto Paulo Martins (entidade que promove o festival "Ver-o-Peso da Cozinha Paraense"), o Instituto ATÁ (sediado em São Paulo), e o Centro de Empreendedorismo da Amazônia (criado em 2015) (SOUSA, 2015).
} 
Mais recentemente, no ano de 2017, a prefeitura de Belém, por meio da Diretoria Executiva da Companhia de Desenvolvimento e Administração da Área Metropolitana de Belém (CODEM), e em parceria com o Fórum das Entidades Empresariais do Estado do Pará, instituiu o Programa "Desenvolve Belém" (BELÉM, 2017) (Quadro 2). Esse programa foi apresentado à mídia e a alguns grupos empresariais locais, como o novo percurso a ser realizado pela prefeitura junto aos seus apoiadores.

\section{QUADRO 2 - PROGRAMA DESENVOLVE BELÉM}

\begin{tabular}{|c|c|c|c|}
\hline Pilares & Projeto & Abragência & Setores \\
\hline \multirow{2}{*}{$\begin{array}{l}\text { Conexões do } \\
\text { Futuro }\end{array}$} & Marina Belém & $\begin{array}{l}\text { Iate Clube até a área da } \\
\text { praça Princesa Isabel }\end{array}$ & $\begin{array}{l}\text { Lazer, esporte, turismo, } \\
\text { Saneamento e transporte }\end{array}$ \\
\hline & Viver Parque das Orquídeas & Augusto Montenegro & Habitação \\
\hline Chão em Dia & Regularização Fundiária & Regularização Fundiária & Habitação \\
\hline \multirow{5}{*}{ Centro Vivo } & Assembleia Paraense & Rua $1^{\circ}$ de Março & Habitação \\
\hline & Espaço Palmeira & Rua Ó de almeida & $\begin{array}{l}\text { Comércio, serviços, } \\
\text { habitação e transporte }\end{array}$ \\
\hline & Travessa Leão XIII & Comércio & Lazer e turismo \\
\hline & Mercado Francisco Bolonha & Ver-o-Peso & Lazer, turismo e educação \\
\hline & $\begin{array}{lll}\text { Palacete } & \text { Pinho } & \text { (Casa } \\
\text { Portugal) } & & \\
\end{array}$ & Cidade Velha & $\begin{array}{l}\text { Comércio, serviços, lazer } \\
\text { e turismo. }\end{array}$ \\
\hline \multirow{3}{*}{$\begin{array}{l}\text { Cidade para } \\
\text { Pessoas }\end{array}$} & \begin{tabular}{|ll} 
Cidade Criativa da \\
Gastronomia
\end{tabular} & $\begin{array}{l}\text { Realizado em diversos } \\
\text { pontos da cidade }\end{array}$ & Turismo \\
\hline & Conviver Parklet Belém & Avenida Brás de Aguiar & Lazer \\
\hline & Mercado de São Brás & Praça Floriano Peixoto & Comércio, lazer e turismo \\
\hline
\end{tabular}

FONTE: Belém (2017).

Organização : Autora.

Tanto o Centro Global de Gastronomia quanto algumas das propostas do programa "Desenvolve Belém" já se encontram em fase de implantação, com previsão de operacionalização dentro dos próximos meses, como o projeto Chão em Dia, para regularização de imóveis de servidores públicos municipais, que já se encontra em fase de cadastramento.

Em três dos quatro pilares apresentados pelo programa demonstra-se uma tendência de formação de espaços para o turismo. A marina "pública", por exemplo, nasce em um cenário marcado por um entorno de grande quantitativo populacional e pelas baixas condições de vida, em uma área que vai do antigo Iate Clube até a praça Princesa Isabel, prevendo-se a composição de locais para apoio náutico, quadras poliesportivas, área para eventos e gastronomia (BELÉM, 2017). Até o momento, não é possível vislumbrar no 
projeto a forma como a maioria dos agentes, principalmente pequenos condutores de embarcações, estarão inseridos.

O fortalecimento do papel do mercado, na figura das agências receptivas de turismo (atravessadoras), das redes de hotéis e, por conseguinte, dos grandes empresários, por vezes excluem os grupos anteriormente estabelecidos, transformando as intervenções urbanas voltadas para o lazer e para o turismo em espetáculo, em estratégias que se desenvolvem e se enfrentam.

Nos últimos anos, diversos eventos realizados pelo poder público e por entidades como a Associação Brasileira de Bares e Restaurantes (ABRASEL) e a Associação Paraense de Supermercados (ASPAS) apresentam o discurso da gastronomia como uma oportunidade de negócios única, capaz de beneficiar desde o pequeno produtor rural até o grande empresário. No entanto, nos ambientes voltados para o lazer e turismo da orla central e sul de Belém, ainda predominam as atividades pertencentes ao circuito inferior, caracterizadas pela presença do emprego familiar, pelos ambulantes informais e pequenos comerciantes que, em alguns casos, atendem a certas normas legais, empresariais e trabalhistas.

Nos quioques, barracas e entre os prestadores de serviços ambulantes do Portal da Amazônia ${ }^{5}$ e do Ver-o-Rio, por exemplo, as operações financeiras são caracterizadas pelo trabalho intensivo, de capital reduzido, de burocracia dispensável, pelo uso de técnicas atuais e residuais, e por uma adaptação própria à tecnologia. Com o crédito pessoal cada vez mais reduzido, o dinheiro líquido ainda se faz muito presente, principalmente entre os vendedores de comidas típicas, de brinquedos e na locação de brinquedos e patins. A limitação tecnológica e de infraestrutura, visto que muitos não possuem pontos fixos para operacionalizar seu negócio, influencia nos custos, diminuindo a possibilidade de pagamento de taxas e diversos impostos.

Entre esses grupos, raras vezes se encontram vínculos empregatícios permanentes, cuja remuneração, situa-se no limite ou abaixo do mínimo vital (SANTOS, 2004). A relação como a clientela ainda é direta e personalizada, os "pedidos de desconto" são comuns, o que torna os preços oscilantes. A publicidade acontece, principalmente, por

\footnotetext{
${ }^{5}$ A autora deste trabalho estudou o perfil dos atuais frequentadores do Portal da Amazônia após inaugurado (CHAVES, 2013). A pesquisa foi fruto do artigo de conclusão do curso de especialização em Gestão de Cidades e Sustentabilidade do Núcleo de Meio Ambiente da Universidade Federal do Pará, no período compreendido entre dezembro de 2012 a agosto de 2013.
} 
iniciativa própria, por meio do "boca a boca" e, mais recentemente, com o auxílio das redes sociais virtuais, muitos mais baratos.

Dentre os componentes do circuito superior, destaca-se a relevância da informação e das finanças, características das empresas do mercado corporativo (SANTOS; SILVEIRA, 2007). Em Belém, a presença de empresas de entretenimento, restaurantes de alto padrão, de consultoria, de produção de informação e de operadoras turísticas é marcante, divulgam e prestam serviços sobre os atrativos turísticos da cidade.

Os projetos governamentais de marketing turístico, contratam consultorias globalizadas, como a Chias Marketing, de origem espanhola, com atuação no Brasil desde os anos 2000, para "atender às carências informacionais emergentes no território brasileiro", mobilizando verdadeiros arsenais de informação (BICUDO, 2006, p. 70). Essa empresa apontou algumas deficiências do setor turístico no Estado, como a ausência de ações promocionais, a pouca estrutura aeroviária e portuária, os preços elevados das passagens e diárias de hotéis, e o pouco conhecimento técnico nas agências locais (PARÁ, 2011).

Os aspectos naturais e culturais de Belém passaram a ser reiteradamente reproduzidos na mídia local e em revistas especializadas do setor de viagens. As ilhas com praias de água doce e o centro histórico da cidade, por exemplo, estão entre as paisagens mais retratadas. Assim, dois agentes são fundamentais para a expansão do circuito superior: a mídia e o Estado.

Para Moraes e Gândara (2016) a mídia modifica a forma como um destino apresenta-se. A postura de turistas e da comunidade local muda e adapta-se de acordo com a lógica do discurso midiático, sendo a espetacularização uma forma de incutir surpresas, fantasias, histórias, marcas emocionais e vivências extraordinárias nos produtos turísticos.

No Pará, organizações sociais como a ABRASEL, o Serviço Brasileiro de Apoio às Micro e Pequenas Empresas (SEBRAE) e a Associação Brasileira de Agências de Viagens (ABAV) criam bancos de dados que permitem acompanhar a comercialização no setor de alimentação e viagens. Esses dados transformam-se em "mercadorias informacionais" (SANTOS; SILVEIRA, 2001, p. 220), pois indicam quais áreas oferecem abundâncias e quais áreas dispõem de carências para o setor. Ademais, outros elementos de forte conteúdo informacional de interesse para os agentes do circuito 
superior são as feiras de exposição, os festivais, os roteiros de visitação e os demais ambientes criados temporariamente.

Em razão da flexibilidade e da adaptação do capital no momento atual, o circuito superior manifesta-se em Belém, principalmente, por meio de sua ligação com o circuito superior marginal, evidenciada em função do uso territorial na área central da cidade, por sua predisposição em infraestrutura e logística (aeroporto internacional, centro de convenções, equipamentos de apoio, como assistência médica, alimentação, segurança e comunicação); e pela localização dos escritórios e filiais de grandes empresas nacionais e multinacionais, de centros financeiros, das sedes de órgãos públicos estaduais e de entidades da sociedade civil.

Empresas multinacionais do setor de viagens, como a Booking.com, a Expedia, o Grupo Trend e a agência Carlson Wagonlit Travel, por mais que não possuam escritórios fixos ou uma presença direta na cidade, desenvolvem tecnologias de informação e de circulação que permitem utilizar e comercializar os produtos e serviços de distribuidores e revendedores locais. Outras grandes firmas, consideradas grandes atacadistas do turismo, como a CVC, a Gol Linhas Aéreas, a Flytour Viagens, a Rede Accor de Hotéis e a Latam, possuem escritórios, representações ou franquias na cidade, destacando-se também por subcontratar e divulgar as prestadoras de serviços turísticos locais pertencentes ao circuito superior marginal.

No circuito superior, a atuação das empresas de serviços gastronômicos, de alto padrão e de clientela selecionada, que adquirem os produtos locais, como o Lá em Casa, localizado na Estação das Docas, e o restaurante D.O.M, localizado no bairro dos Jardins, em São Paulo. Essas firmas possuem expressiva notoriedade por adquirirem produtos da culinária regional, como o chocolate da Ilha do Combu.

Nas subcontratações realizadas pelas grandes marcas turísticas, são selecionadas as maiores ou mais antigas agências de Belém, como é o caso da Valeverde Turismo, que, por sua vez, em muitos momentos subcontrata outras pequenas agências para realizar parte dos roteiros. As agências de receptivo turístico, ao comercializarem pacotes e roteiros personalizados do circuito superior, permitem aos agentes hegemônicos atingir faixas geográficas de mercado sem necessariamente precisar instalarem-se fisicamente nas regiões mais distantes dos seus escritórios centrais. 
Os representantes do circuito superior marginal (re)configuram o espaço de acordo com as necessidades e percurso individual e de grupos, que contratam as grandes agências e essas por sua vez terceirizam os serviços com as empresas locais, criando uma relação de dependência econômica direta. Vale ressaltar que isso não é uma regra, pois muitos viajantes preferem adquirir seus roteiros direto com as agências de receptivo ou “aventuram-se" por conta própria.

No circuito marginal o trabalho acontece em menor proporção se comparado ao circuito superior, preso nos contextos locais, sob limitada modernização tecnológica, operando em pequenas lojas ou unidades residenciais reduzidas a poucos cômodos, em que trabalhadores acumulam funções e cargos, sendo que o capital disponível não se sobressai sobre a questão do trabalho. Em uma das agências de turismo analisadas, localizada em um bairro nobre da cidade, a proprietária é responsável pela compra dos roteiros junto às operadoras e às agências maiores, além de dar assistência aos grupos que realizam as viagens internacionais vendidas pela empresa. Nessa mesma empresa, mãe e filha ocupam cargos de diretoria, demonstrando como a mão de obra familiar faz-se importante também nesse circuito.

$\mathrm{Na}$ busca por mão de obra qualificada, aumentam-se os círculos de cooperação (BICUDO, 2006) entre as agências e as instituições de ensino superior, absorvem-se estudantes dos cursos de turismo e de outras áreas como estagiários, que atuam na assistência em diversas funções, com carga horária reduzida e ajuda financeira para seus custos de transporte e pessoais. Muitas vezes, assim que formados, são contratados em regime trabalhista, aumentando o número de funcionários com formação especializada.

A atuação governamental em prol do circuito superior marginal ocorre por meio de projetos e ações que prestam assistência técnica e informacional específica. Quanto a isso, tem-se como referência a elaboração da Rota Turística Belém-Bragança em 2014, e da Rota Gastronômica da Comida Ribeirinha em 2017, criadas pelo PRODETUR, em que são fornecidos apoio promocional, inventários de oferta turística, equipamentos e capacitações às prefeituras e aos estabelecimentos comerciais inseridos nos roteiros.

As agências de receptivo turístico podem contar também com recursos e acesso à informação por meio de revistas especializadas. Dentre as de nível nacional, destaca-se o Panrotas, empresa de comunicação impressa e virtual, responsável por eventos e inteligência de mercado, fundada em 1974, com sede em São Paulo (PANROTAS, 2014). 
Em nível local, a ABAV-PA conta com o apoio de associados para a publicação da revista "Receptivo Pará".

A demanda turística nasce, muitas vezes, no íntimo do circuito superior, por sua circulação no mercado externo e nas grandes metrópoles nacionais. Contudo, é suprida pelo circuito superior marginal.

Conclui-se que nas atividades turísticas e de lazer realizadas na orla central e sul de Belém prevalecem os negócios do circuito inferior e do circuito superior marginal do turismo, de grau reduzido de tecnologia e de capital, de mão de obra familiar e, em alguns casos, não assalariada, de pouca organização, que adentram no circuito superior a partir da divulgação e comercialização de agentes do poder público, da mídia empresarial e de entidades da sociedade civil organizada.

\section{CONSIDERAÇÕES FINAIS}

Os discursos do poder público que visam dar vida nova ou "resgatar" o patrimônio e cultura na orla de Belém tratam-se, na maioria das vezes, de processos que podem transformar a paisagem, negando-a e deslegitimando-a de outros usos. Esses locais se voltam para uma classe média privilegiada e desejosa de se apoderar do espaço, excluindo dele outros possíveis agentes, usos e funções sociais que poderiam se apropriar dos locais com outra forma menos consumptiva de turismo.

O governo parece não reconhecer as possibilidades existentes nos espaços onde a vida realmente se realiza. Ao invés da criação de centros gastronômicos em locais expostos à segregação social, e não concebidos inicialmente para esse fim, questiona-se por que não são gerados vários pequenos centros culinários nas feiras, nas praças e nos diversos portos espalhados pela cidade, atingindo assim a maior parte da população que se vê cada vez mais compelida ao afastamento dos lugares turísticos.

Destarte, confirma-se o argumento principal deste estudo, de que as atuais propostas de intervenções na orla central e sul de Belém visam refletir as dinâmicas impostas pelo Estado em sua relação com os circuitos econômicos do turismo. E por mais que novas relações da divisão social do trabalho sejam impostas e uma nova dinâmica de produção se aproprie dos diferentes espaços da orla, as dimensões de trabalhos anteriores não são 
completamente extintas, permanecendo os movimentos que colidem com as diferentes formas de dominação do capital.

Por fim, espera-se com esse estudo contribuir com o desafio da pesquisa social em turismo, associando-a uma teoria em constante atualização, como a dos circuitos espaciais econômicos, capaz de permitir compreender como se formam ou se (re)organizam os espaços de lazer e de turismo, que, por sua complexidade, dominam e transformam, principalmente, as economias em emergência.

\section{REFERÊNCIAS}

AMARAL, M. D. B. A guerra das águas: concepções e práticas de planejamento e gestão urbana na orla fluvial de Belém (PA). 2005. 229 f. Dissertação (Mestrado em Planejamento do Desenvolvimento) - Programa de Pós-Graduação em Desenvolvimento Sustentável do Trópico Úmido, Núcleo de Altos Estudos Amazônicos, Universidade Federal do Pará, 2005.

ANA (AGÊNCIA NACIONAL DE ÁGUAS). Rede Hidrometeorológica Nacional. Disponível em: http://www.snirh.gov.br/hidroweb/publico/mapa_hidroweb.jsf. Acesso em: 06 fev.2018.

ANDRADE, T. K.; TAVARES, M. G. O projeto de integração amazônica visto pela turistificação dos lugares. Confins, Paris, v. 14, 2012. Disponível em:

$<$ https://journals.openedition.org/confins/7466>. Acesso em: 29 nov. 2017.

BELÉM. Programa Desenvolve Belém. Belém, 2017. Disponível em: < http://agenciabelem.com.br/multimidiaSGN/anexo/08.12.2017/fc72efdec40f4a6c95133 dac6d4a85be.pdf >. Acesso em: 18 dez. 2017.

BICUDO JR., E. C. O circuito superior marginal: produção de medicamentos e o território brasileiro. 2006. 305 f. Dissertação (Mestrado em Geografia Humana) Departamento de Geografia, Faculdade de Filosofia, Letras e Ciências Humanas, Universidade de São Paulo, São Paulo, 2006.

CARDOSO, A. C. D. A inserção da RMB na Amazônia e na rede urbana brasileira. In: CARDOSO, A.C.D.; LIMA, J. J. F. (Org.). Belém: transformações na ordem urbana. ed. 1, Rio de Janeiro: Letra Capital: Observatório das Metrópoles, 2015.

CATAIA, M; SILVA, S. C. da. Considerações sobre a teoria dos dois circuitos da economia urbana na atualidade. Boletim Campineiro de Geografia, Campinas, v. 3, n. 1, 2013. Disponível em: http://agbcampinas.com.br/bcg/index.php/boletimcampineiro/article/view/111. Acesso em: 05 dez. 2017. 
FAPESPA (FUNDAÇÃO AMAZONIA DE AMPARO A ESTUDOS E PESQUISAS). Anuário Estatístico do Estado do Pará. Disponível em:

http://www.fapespa.pa.gov.br/anuario_estatistico/. Acesso em: 18 dez. 2017.

IBGE (INSTITUTO BRASILEIRO DE GEOGRAFIA E ESTATISTICA). Bases cartográficas contínuas. Disponível em:

ftp://geoftp.ibge.gov.br/cartas_e_mapas/bases_cartograficas_continuas/bcim/versao201 6/shapefile/. Acesso em : 06 fev. 2018.

LAENA (LABORATORIO DE ANÁLISES ESPACIAIS PROFESSOR DOUTOR THOMAS HURTIENNE DO NÚCLEO DE ALTOS ESTUDOS AMAZÔNICOS).

Belém: localização das intervenções turísticas na orla. Belém, 2018.

MALHEIRO, B. C. P. Portos, Portas e Postais: experiências, discursos e imagens produzindo a orla fluvial de Belém (PA). 2009. 189 f. Dissertação (Mestrado em Planejamento do Desenvolvimento) - Programa de Pós-Graduação em Desenvolvimento Sustentável do Trópico Úmido, Núcleo de Altos Estudos Amazônicos da Universidade Federal do Pará, Belém, 2009.

MONTENEGRO, M. R. Globalização, trabalho e pobreza no Brasil metropolitano: o circuito inferior da economia urbana em São Paulo, Brasília, Fortaleza e Belém. 2011. 303 f. Tese (Doutorado em Geografia Humana) - Programa de Pós-Graduação em Geografia Humana, Faculdade de Filosofia, Letras e Ciências Humanas da Universidade de São Paulo, São Paulo, 2011.

MORAES, L. A. de; GÂNDARA, J. M. G. Midiatização e espetacularização do turismo. Turismo e Sociedade. Curitiba, v. 9, n. 1, p. 1-18, 2016.

MOREIRA, E. Belém e sua expressão geográfica. In: PARÁ. Obras reunidas de Eidorfe Moreira. Belém: Cejup, 1989. v.1.

NÓBREGA, W. R. M. Participação popular e as políticas públicas de turismo na Amazônia: o Proecotur no distrito de Mosqueiro, Belém - PA. 2006. 157 f. Dissertação (Mestrado em Cultura e Turismo) - Universidade Estadual de Santa Cruz, Universidade Federal da Bahia, Ilheus, 2006.

PANROTAS. Quem somos. Disponível em: https://midiakit.panrotas.com.br/quemsomos.html. Acesso em: 14 abr. 2018.

PARÁ. Governo do Estado. Plano de desenvolvimento do turismo do estado do Pará (PDT-PA). Belém: Companhia Paraense de Turismo - PARATUR; THR - Assessoria em Turismo Hotelaria e Recreação, 2001.

PARÁ. Governo do Estado. Plano Ver-o-Pará - Plano estratégico de turismo do estado do Pará. Belém: PARATUR; CHIAS Marketing, 2011 (Fase II: o planejamento estratégico). 
PARÁ. Decreto $\mathrm{n}^{\circ} 1.570$, de 29 de junho de 2016. Institui o Programa de Desenvolvimento Sustentável do Estado do Pará - Pará 2030 e dá outras providências.

Diário Oficial do Estado do Pará, n. 33.159, 30 jun. 2016.

PARÁ. Portaria $n^{\circ}$ 010, de 27 de outubro de 2017. Admite e instaura o Procedimento de Manifestação de Interesse Social e autorizar a oitiva da sociedade referente à proposta apresentada pela Organização da Sociedade Civil (OSC) denominada Centro Global de Gastronomia. Diário Oficial do Estado do Pará, n. 33.488, 30 out. 2017.

SANTOS, M. O espaço dividido: os dois circuitos da economia urbana dos países subdesenvolvidos. 2. ed. São Paulo: EDUSP, 2004. (Coleção Milton Santos).

SANTOS, M. Técnica, espaço, tempo: globalização e meio técnico-científicoinformacional. 5. ed. São Paulo: EDUSP, 2008.

SANTOS, M.; SILVEIRA, M. L. O Brasil: território e sociedade no início do século XXI. 3. ed. Rio de Janeiro: Record, 2001.

SEDEME (SECRETARIA DE ESTADO DE DESENVOLVIMENTO ECONÔMICO, MINERAÇÃO E ENERGIA). Balanço do primeiro ano do programa Pará 2030. Disponível em: http://para2030.com.br/wpcontent/uploads/2018/12/Relato\%CC\%81rio-Balanc\%CC\%A7o-do-Primeiro-AnoPara2030.pdf. Acesso em 06 abr 2018.

SILVEIRA, M. L. Crises e paradoxos da cidade contemporânea: os dois circuitos da economia urbana. In: SIMPÓSIO NACIONAL DE GEOGRAFIA URBANA. 10, 2007, Florianópolis. Anais... Florianópolis: Simpurb, 2007, p.1-21.

SOUSA, L. Projeto destaca Belém como Centro de Gastronomia e Biodiversidade. Agência Pará de notícias, Belém, 16 out. 2015. Disponível em:

http://agenciapara.com.br/Noticia/118048/projeto-destaca-belem-como-centro-degastronomia-e-biodiversidade. Acesso em: 24 de nov. 2017.

TRINDADE JÚNIOR, S-C. C. Cidade e cultura na Amazônia: práticas e representações espaciais na orla fluvial de Belém (PA). In: VALENÇA, M. M; COSTA, M. H. B. (orgs.). Espaço, cultura e representação. Natal - RN: EDUFRN, 2005, p. 123-150.

TRINDADE JÚNIOR, S-C. C. Um "skyline” em mutação: o velho centro e as transformações urbanas em Belém. Revista Novos Cadernos Naea, Belém, v. 21, n. 1, p. 57-78, 2018.

TRINDADE JÚNIOR, S-C. C; BARBOSA, E. J. S. Restruturação metropolitana na Amazônia oriental: empreendimentos econômicos e dispersão urbana na área de influência imediata de Belém. GEOUSP: Espaço e Tempo, São Paulo, v. 20, n.2, p. 349-363, ago. 2016. 
Ágila Flaviana Alves Chaves Rodrigues

VELOSO, T.; TRINDADE JÚNIOR, S-C. C. Dinâmicas sub-regionais e expressões metropolitanas na Amazônia brasileira: olhares em perspectiva. Revista Novos

Cadernos Naea, Belém, v. 17, n. 1, p. 177-202, 2014.

VICENTINI, Y. Cidade e história na Amazônia. Curitiba: UFPR, 2004.

XAVIER, D. Arquitetura metropolitana. São Paulo: Annablume, FAPESP, 2007.

Recebido em: 11-05-2019.

Aprovado em: 22-07-2019.

Versão aprovada para publicação em: 23-09-2019. 